\title{
Scale Formation on HSLA Steel during Continuous Casting Part II: The Effect of Surface Conditions
}

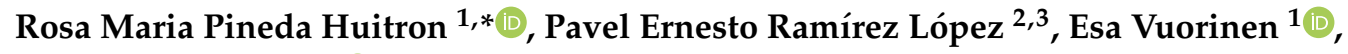 \\ Pooria Nazen Jalali ${ }^{2}{ }^{\mathbb{D}}$, Leonardo Pelcastre ${ }^{1}$ and Maija Kärkkäinen ${ }^{4}$ \\ 1 Department of Engineering Science and Mathematics, Materials Science, Luleå University of Technology, \\ SE 97187 Luleå, Sweden; Esa.Vuorinen@ltu.se (E.V.); Leonardo.pelcastre@1tu.se (L.P.) \\ 2 Casting and Flow Simulation Group, Process Metallurgy Department, SWERIM AB, Aronstorpsvägen 1, \\ SE-97437 Luleå, Sweden; pavel.ramirez.lopez@swerim.se (P.E.R.L.); pooria.jalali@swerim.se (P.N.J.) \\ 3 Materials Science and Engineering, Royal Institute of Technology (KTH), Brinellvägen 23, \\ SE-100 44 Stockholm, Sweden \\ 4 SSAB Europe Oy Raahe Works, Rautaruukintie 155, PL 93, 92101 Raahe, Finland; maija.karkkainen@ssab.com \\ * Correspondence: rosa.maria.pineda.huitron@ltu.se; Tel.: +46-76412-4712
}

Received: 8 August 2020; Accepted: 10 September 2020; Published: 16 September 2020

\begin{abstract}
The present research addresses the effect of surface condition on oxide scale formation at high temperatures such as those experienced during secondary cooling in Continuous Casting. Tests were carried out in clean, as-cast and surfaces covered with casting powder to replicate the oxidation/re-oxidation after the mould. Specimens oxidized at 1000, 1100 and $1200{ }^{\circ} \mathrm{C}$ under dry air and water-vapour conditions revealed that the oxide scale formation is strongly influenced by temperature, environmental and surface conditions. The oxide scale thickness increases with temperature alterations in the surface (e.g., as-cast and covered with powder) where oxides and carbonates from the casting powder accelerate oxidation kinetics leading to thick and unstable scales. A high amount of carbon is present on surfaces covered with casting powder where it diffuses through the oxide scale forming $\mathrm{CO}$ and $\mathrm{CO}_{2}$ which lead to stress accumulation that makes scales prone to defects such as pores, voids and micro-cracks. Ultimately, if wüstite remains attached to the steel surface or inside oscillation marks, it may disturb heat transfer during secondary cooling which has deep industrial implications for crack formation and overall casting yield. Therefore, accurate insights on scale type and growth mechanisms could lead to accurate control of its formation during casting.
\end{abstract}

Keywords: oxide scale; water vapour; surface conditions; continuous casting; casting powder

\section{Introduction}

Temperature, time and environmental conditions influence kinetics during oxidation at high temperatures such as those occurring in Continuous Casting (CC). The first part of this investigation described the oxidation kinetics under dry air and water vapour. Yet, it is unclear if the actual surface conditions (e.g., clean, as-cast or covered with casting powder) play an important role in the development of scale in the secondary cooling of CC. A literature survey revealed that despite considerable interest in oxide growth during rolling, forging and stamping [1-9], a lack of information persists regarding the effect of surface conditions on scale formation during casting processes [10-15]. The majority of previous research has been focused on the impact of the oxide scale during secondary cooling with water sprays (i.e., after the mould), where numerical modelling is the main approach for analysis [1,10,16-20]. Naturally, this has led to oversimplification to facilitate the modelling of heat transfer which often underestimates the physics and mechanisms behind oxide formation. Furthermore, a limited number of investigations have focused on the effect of surface treatment on 
oxidation in stainless steel at relatively high temperatures (i.e., applicable to hot rolling) [21-23]. Likewise, no research was found regarding the effect of casting powder during high-temperature oxidation at casting temperatures (e.g., $>1200{ }^{\circ} \mathrm{C}$ ). The only reference found on a related topic is focused on the effect of surface roughness on an oxide scale [13]. Therefore, the present work seeks to address the gap regarding the influence of surface conditions (e.g., as-cast, clean and covered with powder) on scale formation behaviour.

Casting powders (also known as mould powders) are used in continuous casting to provide thermal insulation and avoid oxidation of the liquid metal by means of a slag bed. (Figure 1a). Initially, casting powders in the slag bed decompose to form a sintered layer. Afterwards, this sintered layer melts to form a slag pool which infiltrates between shell and mould to provide lubrication [24]. Such infiltration process is enhanced by means of mould oscillation at high frequencies (above $100 \mathrm{~Hz}$.) giving rise to marks in the surface of the product, also known as oscillation marks (Figure 1b). Initially, these marks can be filled with slag during solidification in the mould. However, the common industrial perception is that most of these marks are flattened by the rolls which detach the filling slag from the strand surface. Nonetheless, it is natural to expect that some slag remains attached to the surface depending on the depth of the original marks as proven by Saleem et al. in Figure 1c [25]. Yet, no studies could be found regarding the combined effect of casting powders and surface conditions on the oxidation behaviour during CC.

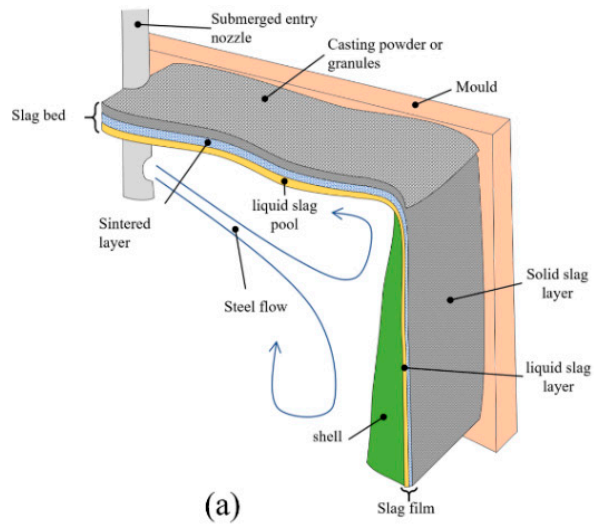

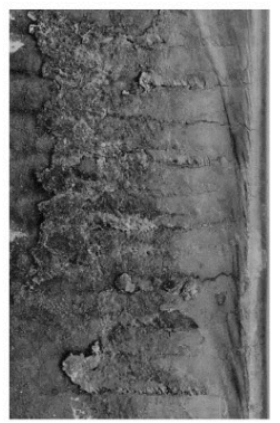

(b)

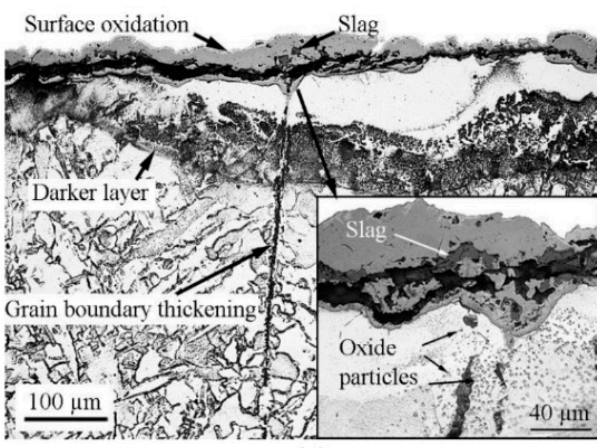

(c)

Figure 1. Schematic illustration of (a) casting powder used in the mould during the continuous casting (CC) process, (b) transverse cracks and oscillation marks formed on a steel slab (courtesy of SSAB) and (c) slag entrapped on the oscillation marks on a steel slab [25] (Reproduced with permission from Saud Saleem, 2016).

\section{Surface Condition and Casting Powder Effects on Oxidation}

Surface conditions are expected to influence oxidation kinetics. For instance, oxidation on clean surfaces leads to a uniform growth of oxide films normal to the surface in the substrate [26-28]. Thus, imperfections on the steel substrate (i.e., as-cast and surface covered with casting powder) can modify the diffusion path for oxidation, oxidation rate, and phase transformations resulting in defects in the oxide films. Thus, oxide scale formation depends on the surface preparation and presence of impurities in the steel substrate [26]. As such, mould powders are of particular interest as one of the main components used during continuous casting. The selection of the casting powder composition depends on the steel grade and casting conditions such as casting speed, mould oscillation and mould dimensions [24-29]. Mould powder constituents include a mixture of oxides (e.g., $\mathrm{Al}_{2} \mathrm{O}_{3}, \mathrm{SiO}_{2}, \mathrm{CaO}_{\text {, }}$ $\mathrm{Na}_{2} \mathrm{O}$ and $\mathrm{MgO}$ ), carbonates (e.g., carbon that decomposed to form oxides and $\left.\mathrm{CO}_{2}\right)$, fluorite $\left(\mathrm{F}_{2} \mathrm{Ca}\right)$ and possibly carbon (C) [29]. The casting powder is fed on top of the molten steel either automatically or manually and the powder in contact with the molten steel at temperatures higher than $1500{ }^{\circ} \mathrm{C}$ will decompose into three different layers. The first layer at the liquid steel/powder interface (melting point for casting powders oscillates between 1000 and $1250^{\circ} \mathrm{C}$ ) will melt and form a liquid slag pool, 
as seen in Figure 1a. The second layer sinters at lower temperatures (i.e., 650 to $1000{ }^{\circ} \mathrm{C}$ ) where the particles coalesce into a semi-solid and porous layer at the liquid slag/powder interface depending on the melting rate which is controlled by the amount of carbon [29-31]. The last layer remains solid and dry at relatively low temperatures (around 200 and $600{ }^{\circ} \mathrm{C}$ ) at the top of the sintered layer [32]. A thin slag film $(<2.0 \mathrm{~mm})$ forms between steel and mould to control heat transfer and lubrication in the process. However, part of this film can be trapped inside the oscillation marks and may influence surface oxidation when in contact with the exterior (e.g., environment rich in oxygen from the air and water from the cooling) after the mould exit. Therefore, the aim of the present work is to systematically study the impact of casting powder on the surface of steel specimens at temperatures similar to those in the secondary cooling zone (i.e., 1000,1100 and $1200^{\circ} \mathrm{C}$ ). This is expected to change the thermophysical properties of the powder in contact with the specimens, which will subsequently modify the oxidation process. A possible mechanism for the interaction of casting powder with the steel substrate is shown in Figure 2.

Casting powder

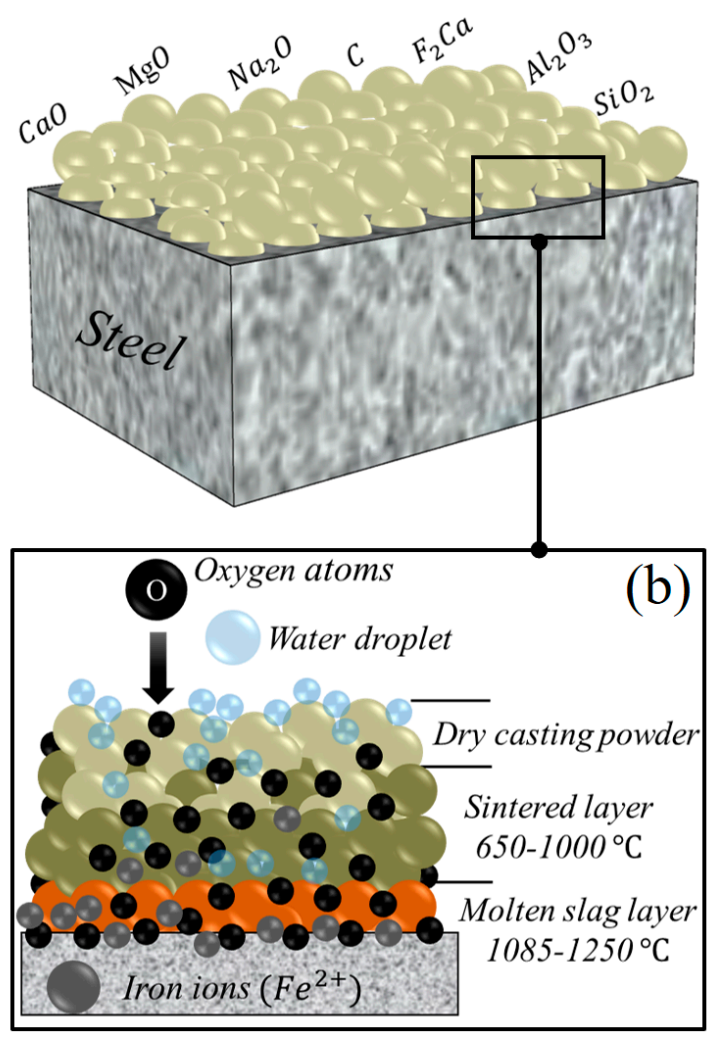

Figure 2. Schematic representation of the interaction of (a) casting powder and the steel substrate during high-temperature oxidation under water vapour, showing the (b) possible casting powder layers formed at high temperatures and its interactions with the oxygen and water droplets from the environment.

Under this assumption, oxide scale growth will be faster due to the presence of oxides and carbon in the casting powder. These elements may influence the oxidation rate leading to an unstable oxide scale growth. In addition, oxidation can be increased by the oxygen in water droplets from the cooling atmosphere. Furthermore, faster oxidation may also occur at temperatures above the melting point for the powder leading to the so-called "liquid oxidation" [26].

The present research seeks to address the lack of information regarding oxidation during CC in relation to different surface conditions. Hence, tests were carried out in clean surfaces, as-cast and 
surfaces covered with casting powder in order to replicate the oxidation/re-oxidation (i.e., secondary oxide scales) formed either during CC or subsequent processing.

\section{Experiment Setup}

Oxidation tests are conducted on specimens taken from a continuously cast slab classified as high strength low alloy (HSLA) steel with $0.15 \mathrm{wt}$. \% C containing $\mathrm{Nb}$ and $\mathrm{V}$ as the main alloying elements.

\subsection{Sampling}

Samples were taken from a slab with dimensions of $210 \mathrm{~mm}$ thickness and $1800 \mathrm{~mm}$ width. The slab was sectioned in the middle to create smaller specimens without surface defects for oxidation experiments. Larger specimens $(150 \mathrm{~mm} \times 100 \mathrm{~mm})$ were used for oxidation under dry conditions while smaller specimens $(50 \mathrm{~mm} \times 70 \mathrm{~mm})$ were used for oxidation under water-vapour conditions as seen in Figure 3.



Figure 3. Specimen identification used for oxidation at high temperature under dry and water-vapour conditions.

\subsection{Oxidation Tests}

Experiments were conducted by applying similar procedures for oxidation tests under dry and water-vapour conditions by using two industrial chambers GPC and N87/H, respectively. Experiments were designed in a pilot-scale to replicate the conditions during secondary cooling in CC, with a special focus on oxidation under water-vapour conditions. Hence, the experimental setup was connected to a boiler to provide steam. At the same time, nitrogen was supplied to protect the chamber from corrosion. Additionally, argon was supplied to provide a protective atmosphere during the heating of the specimens until they reached the target temperature. At this point, only steam was supplied during the complete holding time. Finally, the specimens were taken out of the chamber and let to cool in air at room temperature. The experimental setup is shown in Figure 4.

Before oxidizing specimens at different temperatures, the surface was prepared accordingly as (i) Clean surface: the surface is cleaned with ethanol before oxidation, (ii) As-cast surface: taken from the as-cast slab without surface cleaning and (iii) Casting powder: surface cleaned with ethanol and covered with casting powder with basicity of $1.16 \%$. Oxidation of specimens was conducted at 1000,1100 and $1200^{\circ} \mathrm{C}$ for both tests, while holding time for oxidation under dry and water-vapour conditions was 90 and $45 \mathrm{~min}$, respectively. Thermal cycles are presented in Figure 5. 


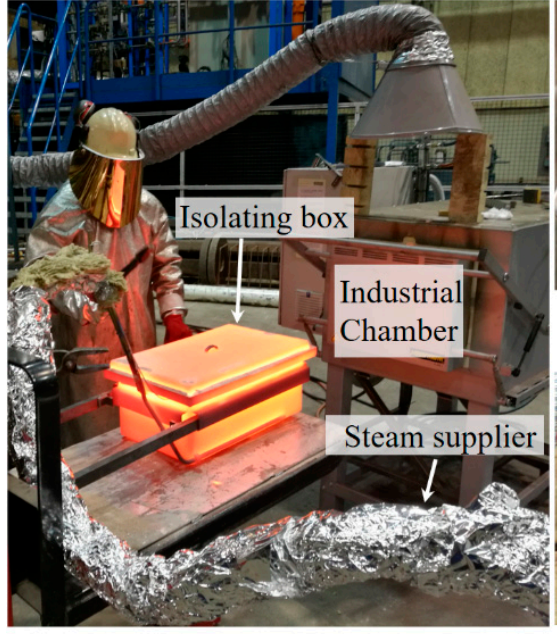

(a)

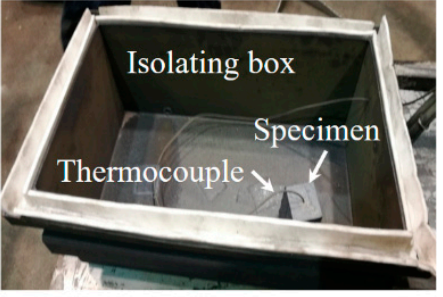

(b)

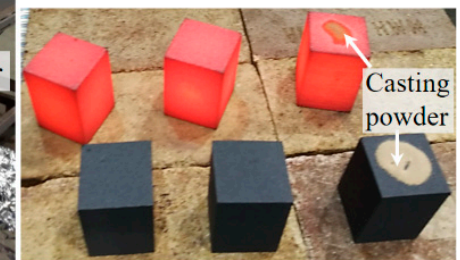

(c)

Figure 4. Experimental setup for (a) oxidation under water vapour atmosphere showing (b) thermocouple position and (c) surface conditons of specimens.
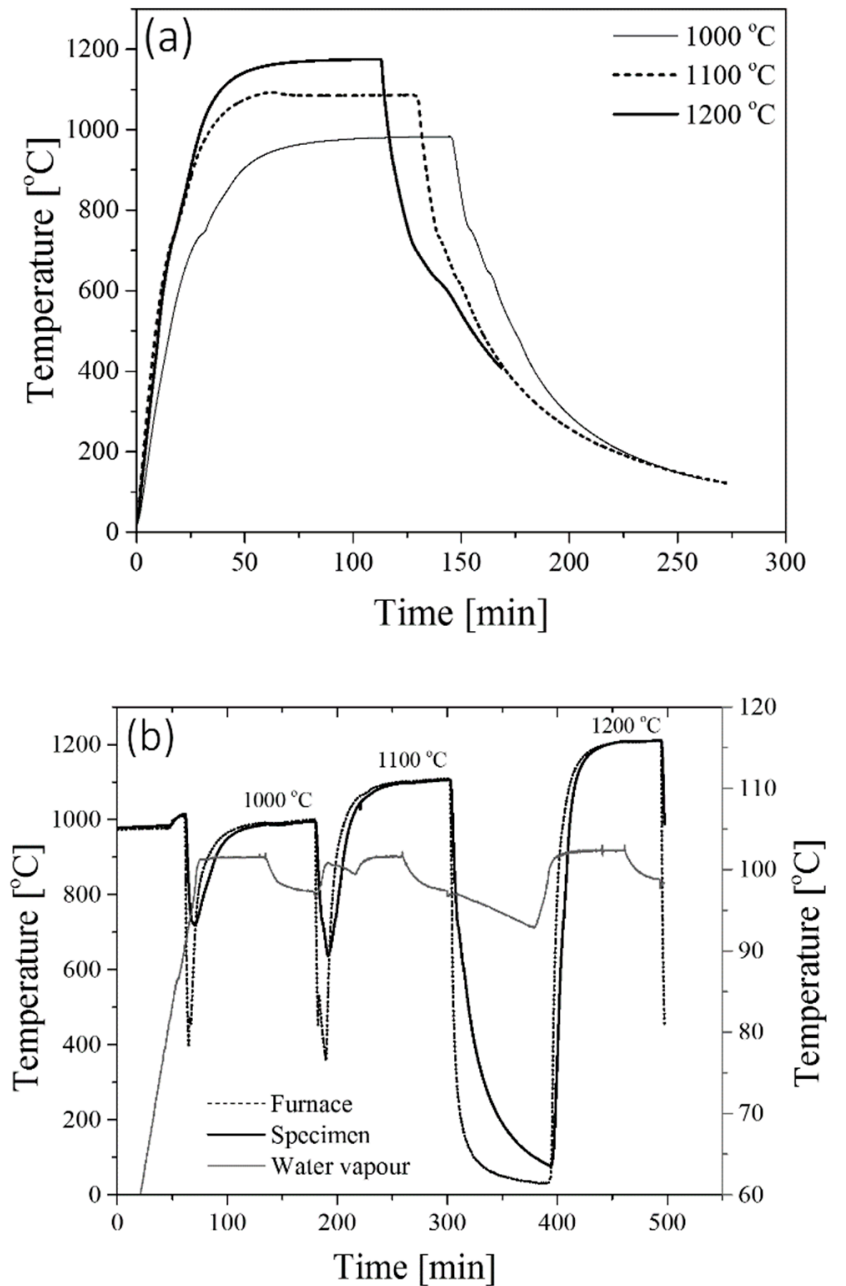

Figure 5. Thermal cycles applied for (a) oxidation under dry air and (b) water-vapour conditions.

After the experiments, the smaller specimens were sectioned and ground with $\mathrm{SiC}$ abrasive papers. Subsequently, specimens were polished using diamond abrasive solutions and colloidal silica. Additionally, the microstructure of the oxide scale was revealed by using different etchant solutions. 
Etching was carried out in sequential steps. Firstly, specimens were submerged in Nital (5\%) solution during 7-10 s. Secondly, surfaces were etched with citric acid and sodium thiocyanate for $30 \mathrm{~s}$ to reveal wüstite and magnetite, respectively [33,34].

Different techniques are used to characterize the oxide scale. For instance, thickness is measured with a precision rule tool in a Jeol JSM-IT300 LV Scanning Electron Microscopy (SEM, JEOL, Peabody, MA, USA). Measurements are taken every $1 \mathrm{~mm}$ throughout the total length of each specimen. In addition, Light Optical microscopy (LOM, Nikon MA200, Nikon Metrology, Novi, MI, USA) is used for microstructural analysis. Energy Disperse X-ray Spectroscopy (EDX, JEOL, Peabody, MA, USA) and X-Ray Diffraction (XRD, Malvern Instruments, Malvern, UK) are used, respectively for chemical and phase analysis. Finally, monochromatic $\mathrm{Cu}-\mathrm{K} \alpha$ radiation with $40 \mathrm{kV}$ and $45 \mathrm{~mA}$ is used for $\mathrm{XRD}$ with an angular $2 \theta$ range between 20-120 degrees with $1 \mathrm{~h}$ scanning time for each specimen.

\subsection{Nanoindentation}

Micromechanical properties were determined through nanoindentation tests. This technique allows the understanding of the elastic-plastic behaviour of phases formed in the oxide scales. Measurements are conducted on a specimen oxidized under water vapour at $1200{ }^{\circ} \mathrm{C}$, and covered with casting powder. A NanoTest Vantage system from Micro Materials Ltd., with a diamond Berkovich indenter-tip is used. A load control of $50 \mathrm{mN}$ after $25 \mathrm{~s}$, unloading time of $20 \mathrm{~s}$, and dwell time at the maximum load of $15 \mathrm{~s}$ is applied during testing. Hardness is calculated based on the Oliver and Parr method [35]. The cross-section of the oxide scale is divided into sections identified as steel, steel/oxide interface, middle, mixed and oxide/oxygen interface, as shown in Figure 6.

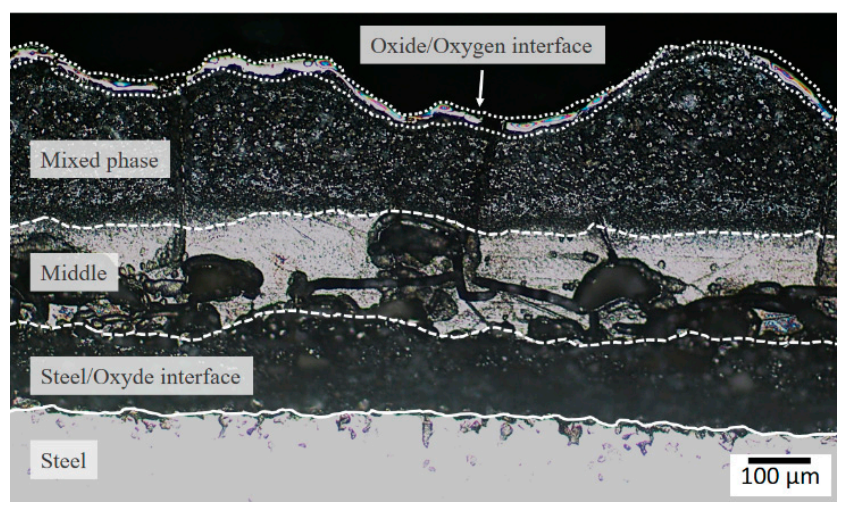

Figure 6. Micrograph showing zones used for nanoindentation tests.

\section{Results}

\subsection{Characterization of Scale}

Comparison of oxide scale formed on different surfaces under dry and water-vapour conditions revealed that the oxide grows with temperature as shown in Figure 7. It can also be observed that surface conditions may change the kinetics of oxidation. For instance, oxidation under a water-saturated atmosphere seems to increase exponentially with temperature while oxidation under dry air produces constant linear growth. Steel surfaces oxidized under dry conditions indicate that the maximum scale thickness of the steel can reach values up to $700 \mu \mathrm{m}$ after $90 \mathrm{~min}$ holding time. Moreover, changes in thickness are directly influenced by the surface treatment of the specimen. For instance, the oxide scale formed on clean surfaces fluctuates from 366 to $455 \mu \mathrm{m}$ with negligible influence of temperature. In contrast, the as-cast surface leads to significant changes in thickness (i.e., 200, 400 and $700 \mu \mathrm{m}$ for 1000,1100 and $1200{ }^{\circ} \mathrm{C}$, respectively). 


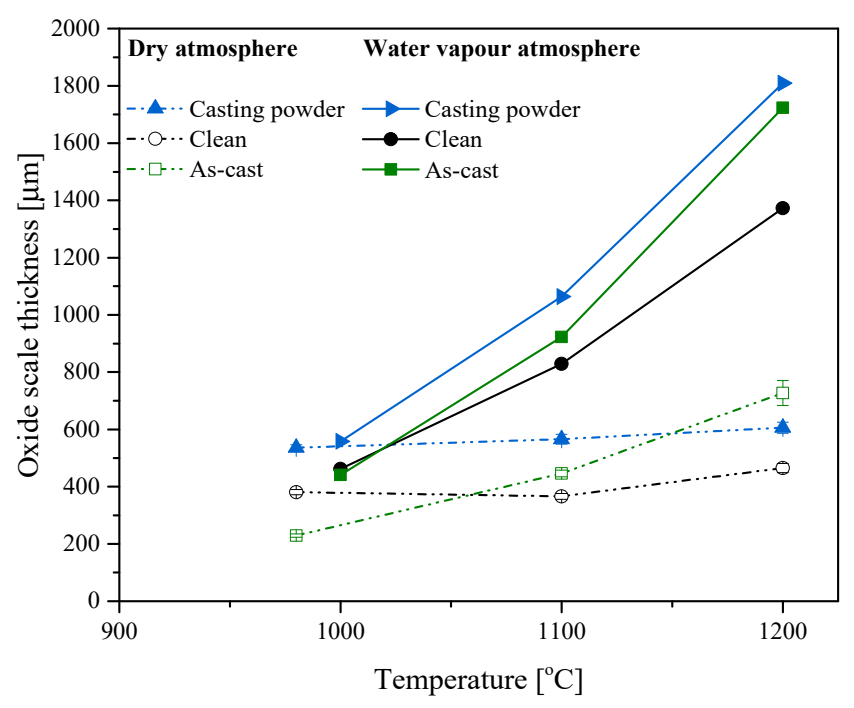

Figure 7. Oxide scale thickness as a function of temperature.

Surfaces covered with casting powder exhibit the thickest scale at 1000 and $1100{ }^{\circ} \mathrm{C}$ (536 and $566 \mu \mathrm{m}$ respectively); however, the thickness is almost the same between 1100 and $1200{ }^{\circ} \mathrm{C}(566$ and $606 \mu \mathrm{m})$.

Oxidation under water vapour atmosphere after $45 \mathrm{~min}$ holding time, clearly shows that the oxide scale grows significantly when the temperature increases. At the lowest temperature (i.e., 1000), the oxide scale grows with a similar thickness on different surface conditions with values between $462 \mu \mathrm{m}$ and $558 \mu \mathrm{m}$. In fact, important changes were found for 1100 and $1200{ }^{\circ} \mathrm{C}$ in all surface conditions. At $1100{ }^{\circ} \mathrm{C}$ the clean surface displays a thinner oxide scale with $829 \mu \mathrm{m}$, followed by the thickness in the as-cast surface, which revealed values of $923 \mu \mathrm{m}$. Thicker oxides were formed on the surface covered with casting powder (i.e., $1064 \mu \mathrm{m}$ ). Nonetheless, the thickest oxides were found at $1200{ }^{\circ} \mathrm{C}$ with values of $1373 \mu \mathrm{m}$ for a clean surface, $1724 \mu \mathrm{m}$ for as-cast surface and $1809 \mu \mathrm{m}$ for the surface covered with casting powder.

Comparison of the oxide scale thickness obtained after the CC process was performed (reference specimen), and it was observed that after the CC process the thickness reached values of $250 \mu \mathrm{m}$. This value was very close to those specimens oxidized at $1000^{\circ} \mathrm{C}$ under dry air but far from values obtained after water-vapour conditions. The reason for these differences is because the oxide scales during experiments in the pilot plant are performed at specific temperatures during heating, while the oxide scale in the real process is continuously formed during cooling. Therefore, the oxide scale formed at $1200^{\circ} \mathrm{C}$, when in contact with the support rolls and the water pressure from the nozzles, may promote the detachment of the oxide scale from the beginning of the secondary cooling (bender) and become thinner when reaching the straightening $\left(1000^{\circ} \mathrm{C}\right)$. Those factors will reduce the oxidation process at the surface of the oxide scale, which may slow the kinetics of oxidation.

A comparison of the oxide scale thickness formed under dry and water-vapour conditions is shown in Table 1. 
Table 1. Comparison of oxide scale thickness formed under dry air and water-vapour conditions.

\begin{tabular}{cccc}
\hline \multirow{2}{*}{$\mathbf{T}\left({ }^{\circ} \mathbf{C}\right)$} & Surface Condition & \multicolumn{2}{c}{ Average Thickness } \\
\cline { 3 - 4 } & & \multicolumn{2}{c}{$(\boldsymbol{\mu m})$} \\
\cline { 3 - 4 } & & Dry Air & Water Vapour \\
\hline \multirow{3}{*}{1000} & Clean & 381 & 462 \\
& As-Cast & 229 & 441 \\
& Casting Powder & 536 & 558 \\
\multirow{3}{*}{1100} & Clean & 366 & 829 \\
& As-Cast & 446 & 923 \\
& Casting Powder & 566 & 1064 \\
\hline \multirow{2}{*}{1200} & Clean & 465 & 1373 \\
& As-Cast & 727 & 1724 \\
& Casting Powder & 606 & 1809 \\
\hline
\end{tabular}

\subsection{Defects in Oxide Scale}

The combination of temperature, surface condition and environment has a strong influence on oxidation kinetics resulting in physical and mechanical changes in the scale. These changes cause defects at the steel/oxide interface and the steel substrate, which results in unstable and fragile oxides. In particular, pores, voids, gaps and micro-cracks were found for all specimens oxidized at 1000, 1100 and $1200{ }^{\circ} \mathrm{C}$ on a clean, as-cast and surface covered with casting powder. Figure 8 shows a representation of different defects found in the oxide scale.

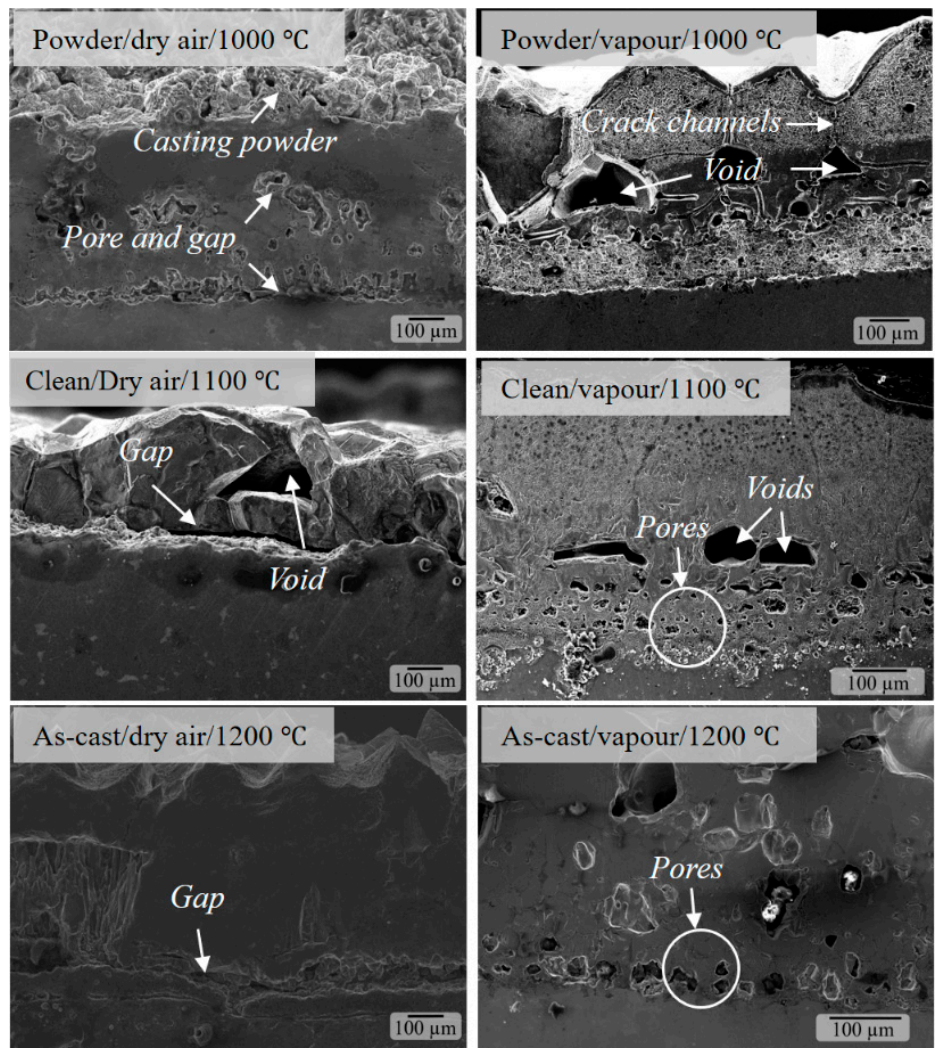

Figure 8. SEM micrographs of defects in oxide scales formed under dry air and water-vapour conditions.

Observations show that surface conditions change the size and number of defects, which increase with temperature. Likewise, the morphology of oxides changes with environmental conditions (e.g., dry and water-saturated atmosphere). Oxidation under dry air generates fewer defects compared 
to water-vapour conditions, whereas pores and voids are more significant in oxides formed on clean surfaces than as-cast and covered with casting powder. Additionally, gaps formed at $1100{ }^{\circ} \mathrm{C}$ on the as-cast surface promoting separation of $50 \mu \mathrm{m}$ between the oxide scale and the substrate. In contrast, small gaps and more stable oxides appeared on clean and casting powder surfaces at 1000 to $1100{ }^{\circ} \mathrm{C}$ but stability decreases at $1200^{\circ} \mathrm{C}$. Such defects resulted in fragile scales that detached in a brittle manner leading to spallation from the surface to the middle part of the oxide scale.

Oxidation under water vapour produces dense scales with high adhesion to the substrate, as well as large defects starting from the steel/substrate interface to the outer layer (cf. scales formed under dry air). However, the size and instability of defects increase as the temperature increases.

The formation of defects on clean surfaces revealed better adhesion and stability than the as-cast and casting powder surfaces. The casting powder surfaces produce the formation of pores, large voids and micro-cracks along the oxide scale, which grow significantly with temperature (i.e., 1100 and $1200{ }^{\circ} \mathrm{C}$ ). These defects create an unstable growth due to the components from the casting powder, which can promote a fast diffusion of elements through the oxide scale.

The development of defects in oxide scales is associated with different mechanisms. In fact, pores are related to the formation of gases entrapped in the oxide scale. The formation of small pores reduces the Young's modulus of the scale, while large pores act as stress concentrators and weaken the oxide, forming cracks $[8,26,28,36]$. Voids grow due to mechanical deformation (i.e., elastic/plastic) of the scales occurring on a static or dynamic motion. Such voids can glide or climb into grain boundaries and consequently form gaps [26].

Finally, roughness changes with surface and environmental conditions. For instance, oxidation under water vapour leads to significant roughness compared to oxidation under dry conditions, especially for the as-cast and surface covered with casting powder. A possible explanation of this is related to the non-uniform surfaces created by the casting powders and the previous oxide scale formed in the CC process, which change its morphology after re-oxidizing the steel.

The oxide scales formed on as-cast surfaces can be related to those formed during subsequent processing (i.e., hot rolling, stamping, forging) where the material is re-heated to temperatures close to $1200{ }^{\circ} \mathrm{C}$. Consequently, if the oxide scale from the CC is not removed, it can lead to secondary oxide scale formation promoting surface defects on steel slabs.

\subsection{Phase Analysis}

X-ray diffraction measurements were performed on specimens oxidized under water vapour at different temperatures and surface conditions. The measurements were conducted on top of the oxide layer (i.e., bulk samples with 3-5 mm thickness) using a beam mask of $10 \mathrm{~mm}$. Diffraction patterns were identified by the Rietveld refinement method.

Diffraction patterns in Figure 9 show the evolution of Wüstite $\left(\mathrm{Fe}_{1-x} \mathrm{O}\right)$, magnetite $\left(\mathrm{Fe}_{3} \mathrm{O}_{4}\right)$ and hematite $\left(\mathrm{Fe}_{2} \mathrm{O}_{3}\right)$ on specimens oxidized at 1000,1100 and $1200{ }^{\circ} \mathrm{C}$ on clean, as-cast and surface covered with casting powder.

A combination of $\mathrm{Fe}_{1-x} \mathrm{O}, \mathrm{Fe}_{3} \mathrm{O}_{4}$ and $\mathrm{Fe}_{2} \mathrm{O}_{3}$ formed on specimens oxidized on the as-cast surface. As the temperature increases to $1100{ }^{\circ} \mathrm{C}$, the $\mathrm{Fe}_{1-x} \mathrm{O}$ disappears and only $\mathrm{Fe}_{3} \mathrm{O}_{4}$ and $\mathrm{Fe}_{2} \mathrm{O}_{3}$. remain, out of which $\mathrm{Fe}_{2} \mathrm{O}_{3}$ appear as the dominant phase. Furthermore, $\mathrm{Fe}_{2} \mathrm{O}_{3}$ forms at $1200{ }^{\circ} \mathrm{C}$ since $\mathrm{Fe}_{1-x} \mathrm{O}$ is only apparent as a small fraction due to a reversible reaction $\left(\mathrm{Fe}_{1-x} \mathrm{O}\right.$ can form from $\left.\mathrm{Fe}_{2} \mathrm{O}_{3}\right)$ [37]. The morphology of $\mathrm{Fe}_{1-x} \mathrm{O}, \mathrm{Fe}_{3} \mathrm{O}_{4}$ and $\mathrm{Fe}_{2} \mathrm{O}_{3}$ can be observed in Figure 10. The $\mathrm{Fe}_{1-x} \mathrm{O}$ forms at the steel/oxide interface (light colour), followed by $\mathrm{Fe}_{3} \mathrm{O}_{4}$ as the middle phase (brown colour), and $\mathrm{Fe}_{2} \mathrm{O}_{3}$ as the thinnest phase (white colour) formed at the oxide/oxygen interface. A mixture of $\mathrm{Fe}_{3} \mathrm{O}_{4}$ and $\mathrm{Fe}_{2} \mathrm{O}_{3}$ is formed between the magnetite and hematite with the presence of small and large grains.

Subsequently, clean surfaces revealed high fractions of $\mathrm{Fe}_{1-x} \mathrm{O}, \mathrm{Fe}_{3} \mathrm{O}_{4}$ and $\mathrm{Fe}_{2} \mathrm{O}_{3}$ at $1000{ }^{\circ} \mathrm{C}$. However, as the temperature increases to $1100{ }^{\circ} \mathrm{C}, \mathrm{Fe}_{3} \mathrm{O}_{4}$ and $\mathrm{Fe}_{2} \mathrm{O}_{3}$ remain but $\mathrm{Fe}_{1-x} \mathrm{O}$ disappears while at $1200{ }^{\circ} \mathrm{C}$ only $\mathrm{Fe}_{3} \mathrm{O}_{4}$ remains as the dominant phase. Figure 11 shows the phases formed on a clean surface. 


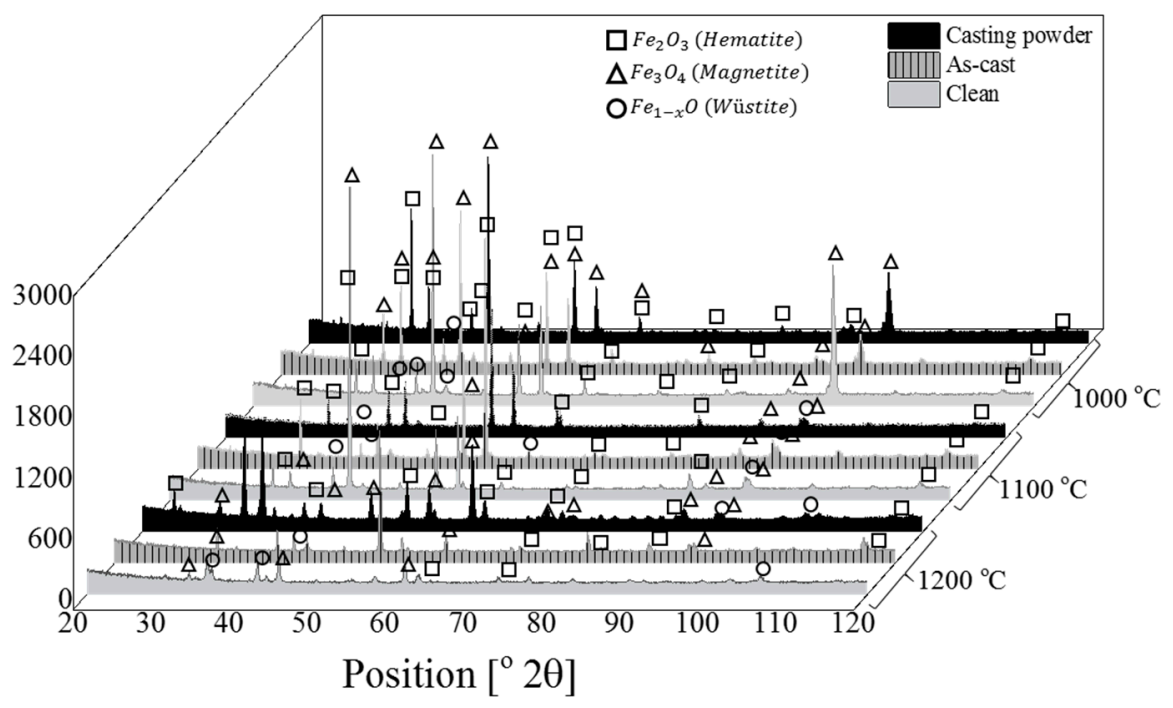

Figure 9. X-ray diffraction patterns of oxide scales formed on as-cast, clean and casting powdered surfaces under water-vapour conditions.

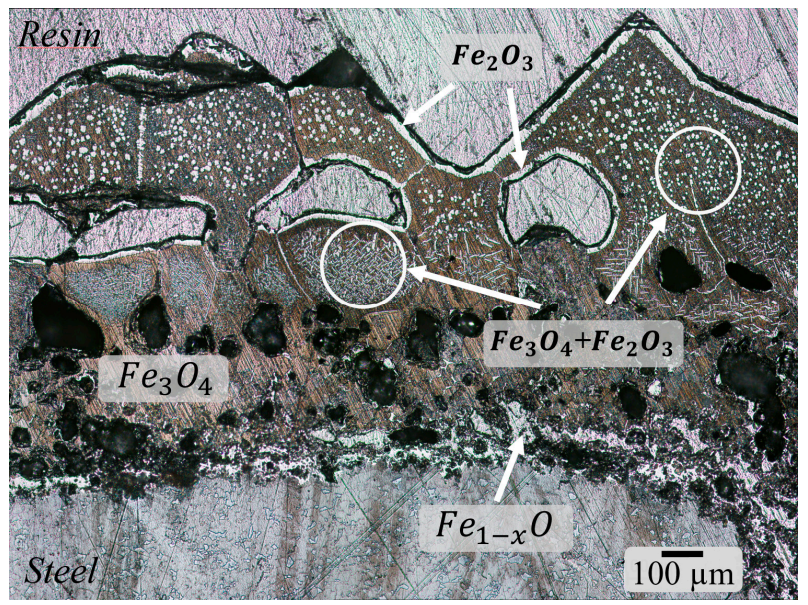

Figure 10. Wüstite $\left(\mathrm{Fe}_{1-x}\right)$, magnetite $\left(\mathrm{Fe}_{3} \mathrm{O}_{4}\right)$ and hematite $\left(\mathrm{Fe}_{2} \mathrm{O}_{3}\right)$ phases formed at $1000{ }^{\circ} \mathrm{C}$ on an as-cast surface.

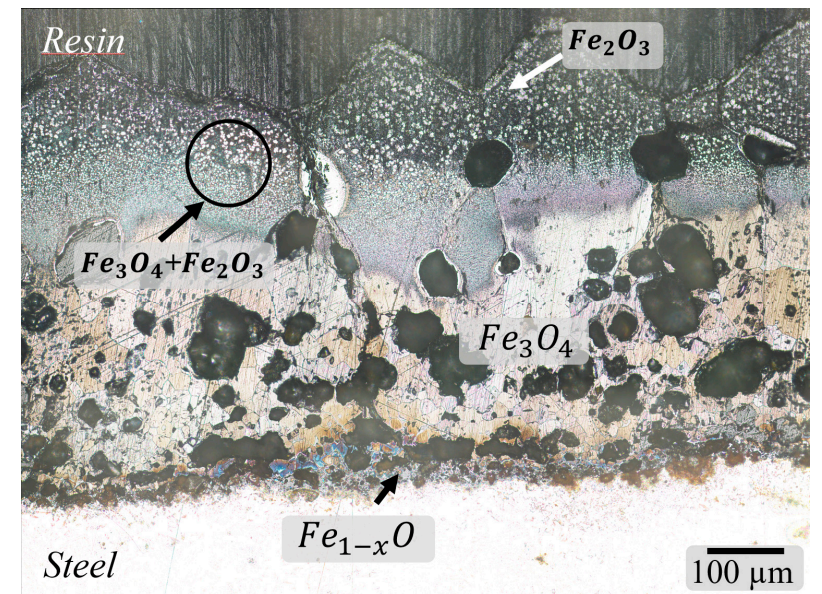

Figure 11. Wüstite $\left(\mathrm{Fe}_{1-x}\right)$, magnetite $\left(\mathrm{Fe}_{3} \mathrm{O}_{4}\right)$ and hematite $\left(\mathrm{Fe}_{2} \mathrm{O}_{3}\right)$ phases formed at $1000{ }^{\circ} \mathrm{C}$ on a clean surface. 
The volume fraction of phases formed on surfaces covered with casting powder differs from those in as-cast and clean surfaces. For instance, $\mathrm{Fe}_{3} \mathrm{O}_{4}$ and $\mathrm{Fe}_{2} \mathrm{O}_{3}$ dominate the oxide scale at 1000 and $1200{ }^{\circ} \mathrm{C}$. In contrast, a high fraction of $\mathrm{Fe}_{1-x} \mathrm{O}$ appears only for specimens oxidized at $1100{ }^{\circ} \mathrm{C}$ possibly due to the influence of oxides from the casting powder. Figure 12 shows the example of phases formed on the steel covered with casting powder.

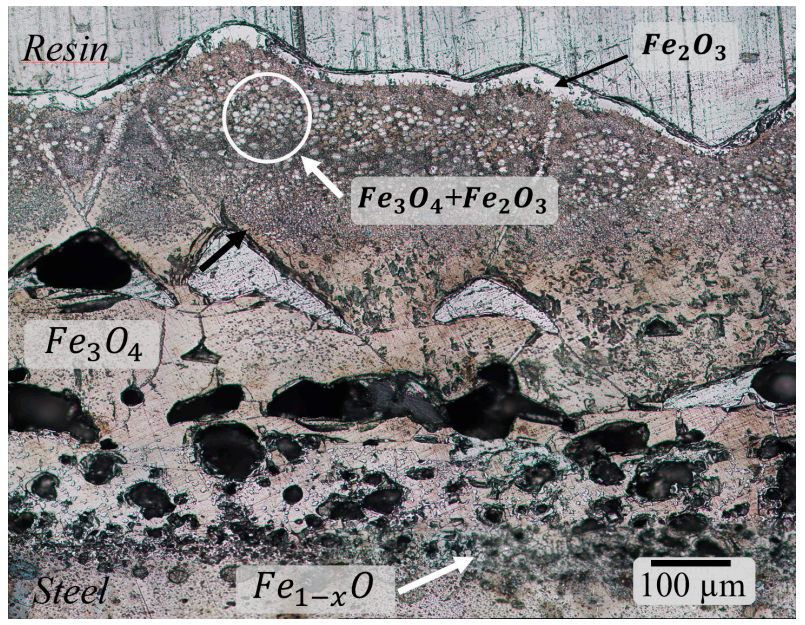

Figure 12. Wüstite $\left(\mathrm{Fe}_{1-x}\right)$, magnetite $\left(\mathrm{Fe}_{3} \mathrm{O}_{4}\right)$ and hematite $\left(\mathrm{Fe}_{2} \mathrm{O}_{3}\right)$ phases formed at $1000{ }^{\circ} \mathrm{C}$ on a surface covered with casting powder.

The volume fraction of phases obtained for all specimens can be observed in Table 2 .

Table 2. Volume fraction of phases formed on specimens oxidized under water-vapour conditions.

\begin{tabular}{ccccc}
\hline $\mathbf{T}\left({ }^{\circ} \mathbf{C}\right)$ & Surface Condition & Wüstite $\left(\mathrm{Fe}_{1-\boldsymbol{x}} \mathbf{O}\right)$ & Magnetite $\left(\mathrm{Fe}_{3} \mathbf{O}_{4}\right)$ & $\mathbf{H e m a t i t e ~}_{\left(\mathrm{Fe}_{2} \mathbf{O}_{3}\right)}$ \\
\hline \multirow{3}{*}{1000} & Clean & 12.5 & 34.4 & 53.2 \\
& As-Cast & 12.1 & 36.5 & 51.3 \\
& Casting Powder & - & 39.6 & 60.4 \\
\hline \multirow{3}{*}{1100} & Clean & - & 42.9 & 57.1 \\
& As-Cast & - & 14.1 & 85.9 \\
& Casting Powder & 32.2 & - & 67.8 \\
\hline \multirow{2}{*}{1200} & Clean & - & - & 98 \\
& As-Cast & 17.1 & - & 82.1 \\
& Casting Powder & - & 40.1 & 59.9 \\
\hline
\end{tabular}

\section{Discussion}

Scale growth is analysed by means of a variety of techniques including phase analysis as well as the effect of casting powder on oxidation kinetics, micromechanics and carbon content on oxidation behaviour.

\subsection{Phase Analysis}

The analysis revealed a random distribution of wüstite, magnetite and hematite formed on a clean, as-cast and surface covered with casting powder. Moreover, no direct relationship was found between the volume fraction of phases and temperature as shown in Figure 13. 


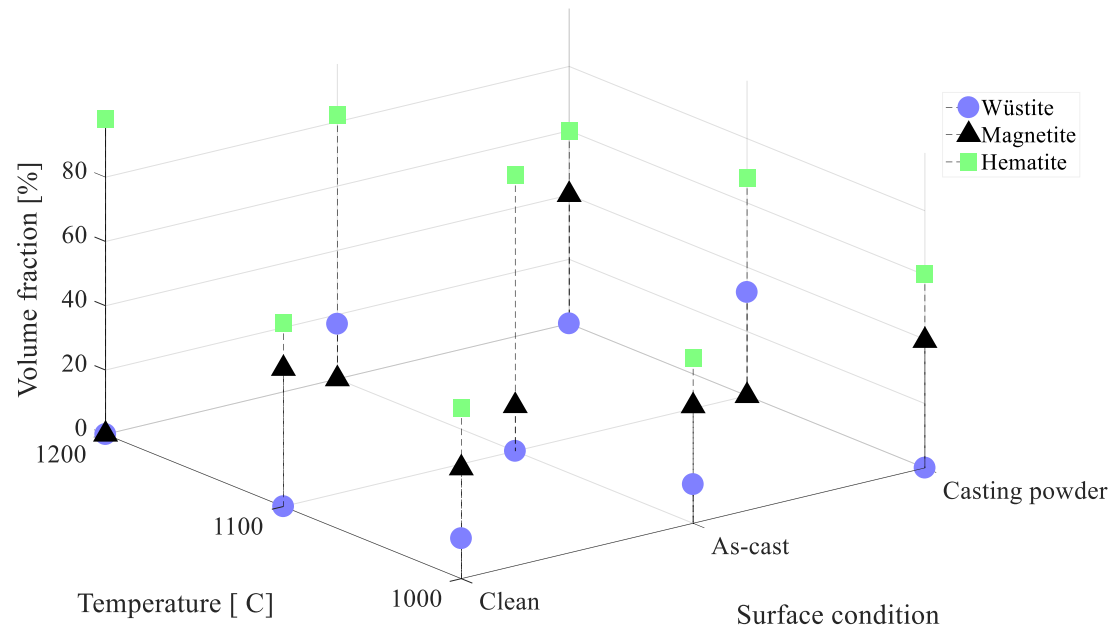

Figure 13. Volume fraction of wüstite, magnetite and hematite on specimens oxidized under water-vapour conditions.

Generally, wüstite $\left(\mathrm{Fe}_{1-x} \mathrm{O}\right)$ is randomly distributed for all cases. Therefore, the clean surface revealed the lowest fraction $(12.5 \%)$ at the lowest temperature $\left(1000{ }^{\circ} \mathrm{C}\right)$. The same phase appears on the as-cast surface at the lowest and highest temperatures with similar volume fractions (12 and $17 \%$ at 1000 and $1200^{\circ} \mathrm{C}$ respectively). The highest fraction of wüstite is formed on the surface covered with casting powder with $32 \%$ at $1100^{\circ} \mathrm{C}$; yet, no wüstite was found at 1000 and $1200^{\circ} \mathrm{C}$. This behaviour can be possibly due to the detachment of the oxide scale during experiments, which suppresses the wüstite formation. In contrast, magnetite $\left(\mathrm{Fe}_{3} \mathrm{O}_{4}\right)$ is homogeneously distributed at the lowest temperature $\left(1000{ }^{\circ} \mathrm{C}\right)$, while an inhomogeneous distribution appears at 1100 and $1200^{\circ} \mathrm{C}$ without relationship to surface condition. Hematite $\left(\mathrm{Fe}_{2} \mathrm{O}_{3}\right)$ is also homogeneously distributed for all cases. Such a fraction increases with temperature and changes by modifying the steel surface. Hematite was the predominant phase for all specimens.

An important observation made is that the pre-existing conditions on the surface have a cumulative effect on scale growth. For instance, growth on clean surfaces results in lower fractions compared to as-cast while casting powder causes the highest fraction growth of all.

The roughness in the scale surface influenced the measurements during x-ray diffraction experiments. Under these circumstances, the continuity of the x-rays may be affected leading to micro-adsorption, which is caused both by bulk porosity and surface roughness [38]. An alternative approach using powder samples to minimize the effect of surface roughness in volume fraction measurements would be suitable for this case.

\subsection{Effect of Casting Powder on Oxidation Kinetics}

Casting powder is important during oxidation because it modifies the thermophysical properties of the scale. In fact, a thin layer of molten slag forms at the steel/powder interface, especially for oxidation occurring at 1100 and $1200^{\circ} \mathrm{C}$. Then, a thick sintered layer occurs at $1000^{\circ} \mathrm{C}$ at the slag/powder interface whereas a thin sintered layer occurs at $1100^{\circ} \mathrm{C}$. The unmelted casting powder remains solid at the surface. Large channels can act as preferential sites for casting powder to penetrate and consequently modify the oxidation process (e.g., diffusion rate). For instance, a specimen oxidized with casting powder at $1000{ }^{\circ} \mathrm{C}$ shows the presence of channels formed from cracks that propagate through the oxide scale as seen in Figure 14.

Notably, oxides and carbonates in the casting powder can diffuse through the scale modifying its structure. However, some of the particles coming from the casting powder can be trapped on the steel substrate and remaining in the oxide scale during growth. For instance, aluminium, silicon and calcium were found at the oxide/powder interface (Figure 15). These oxides are possible culprits for faster diffusion of oxygen atoms throughout the scale, especially under water-vapour atmospheres. 


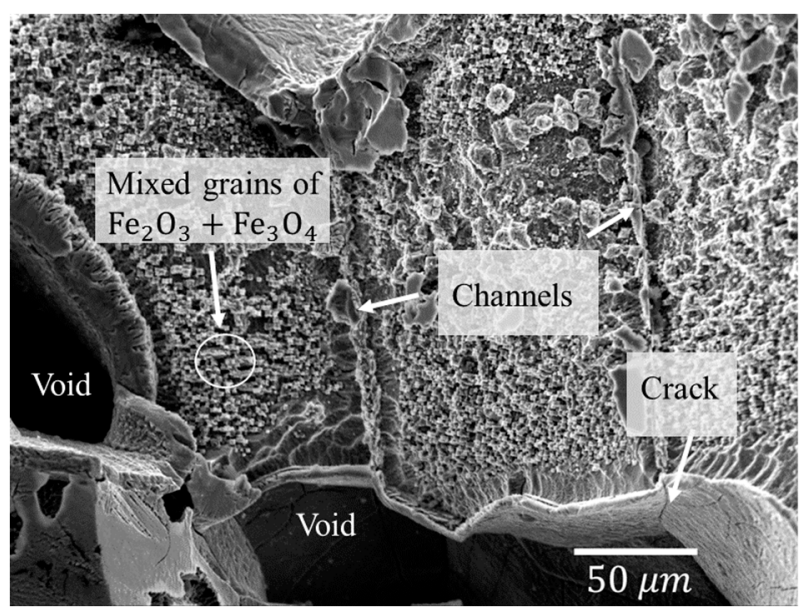

Figure 14. SEM micrograph showing the channels formed from cracks in the oxide scale. Specimen oxidized under water-vapour conditions with casting powder at $1000^{\circ} \mathrm{C}$.
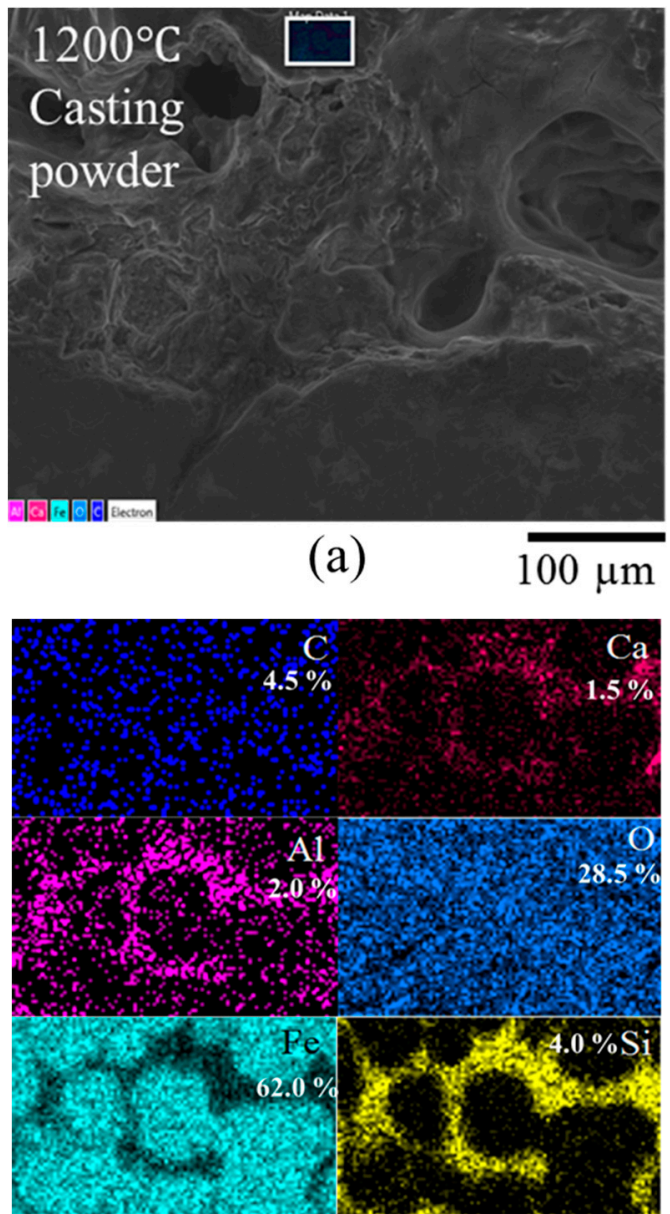

(b) $\overline{25 \mu \mathrm{m}}$

Figure 15. SEM-elemental analysis (EDX) mapping of a specimen covered with casting powder oxidized at $1200{ }^{\circ} \mathrm{C}(\mathbf{a})$, showing the distribution of chemical elements (b).

At the atomic level, it is likely that the high amount of oxygen from the casting powder and environmental conditions accelerate the pick-up of iron atoms forming thicker oxide scales with high density. This type of growth may also lead to the formation of defects in the oxide that may; in some cases, stop oxidation or continue the diffusion process if cracks develop through the scale. These cracks 
act as preferential paths for the diffusion of oxygen. Figure 16, shows an example of an oxide scale formed at high temperature (i.e., $1000^{\circ} \mathrm{C}$ ) on a surface covered with casting powder.

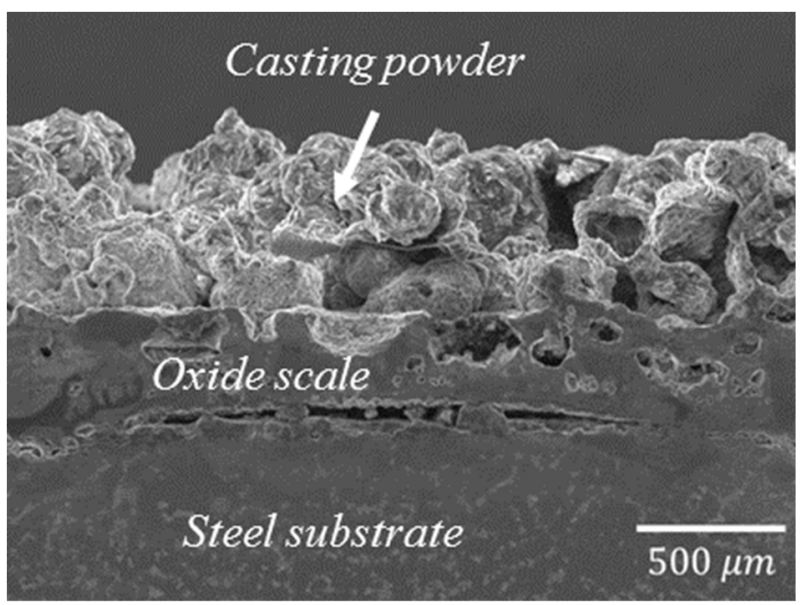

Figure 16. SEM micrograph showing an oxide layer on a surface covered with casting powder under dry conditions.

\subsection{Effect of Casting Powder on Micromechanics}

The results in Figure 17 show a gradual increment of hardness $\left(H_{N}\right)$ from the inner to the outer layer of the oxide. The $H_{N}$ of wüstite (at the steel/oxide interface) ranges between 0.5 and $5.5 \mathrm{GPa}$. Higher values of magnetite (middle phase) are found between 5.7 and $6.3 \mathrm{GPa}$. Hematite (at the oxide/oxygen interface) revealed the highest hardness values between 6 and 7 GPa. Additionally, the mixed-phase composed by magnetite and hematite shows intermediate values from 5 to $7 \mathrm{GPa}$. Finally, the steel substrate revealed hardness values between 3 and $4 \mathrm{GPa}$. The hardness in the steel substrate is taken as a reference to identify the interface between substrate and scale.

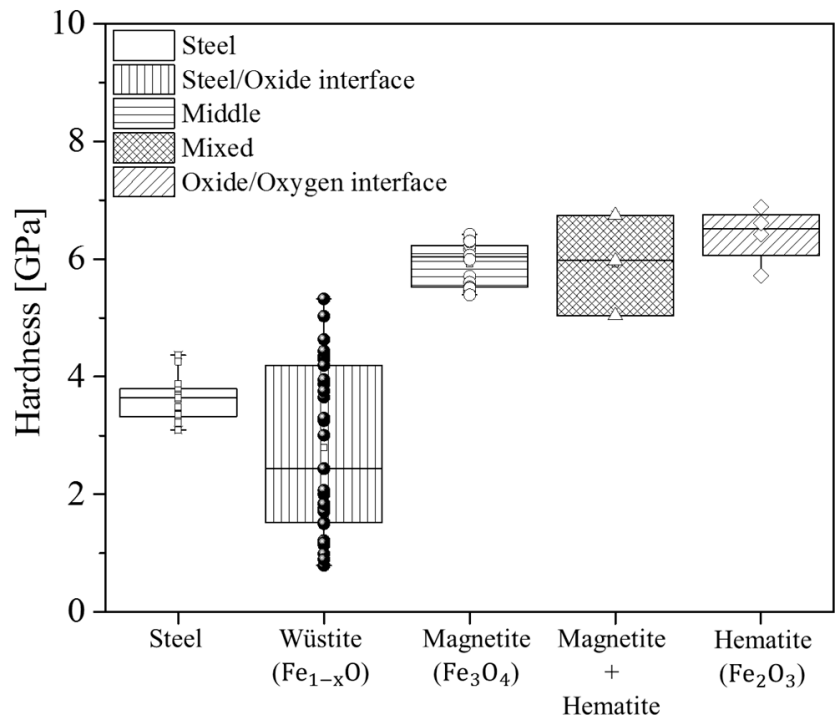

Figure 17. Nano-hardness values of phases in oxide scales (wüstite, magnetite and hematite) formed on a specimen covered with casting powder.

The plastic properties in oxides formed on a surface covered with casting powder in Figure 18 revealed higher plasticity for wüstite and lower for magnetite and hematite phases. For instance, the plastic work in wüstite ranges from 5 to $30 \mathrm{~nJ}$. In contrast, lower values were found for magnetite 
between 2 to $8 \mathrm{~nJ}$. The plastic work increases for the mixed zone (magnetite and hematite) and hematite phase, which values comprise between 7 and 9 nJ.

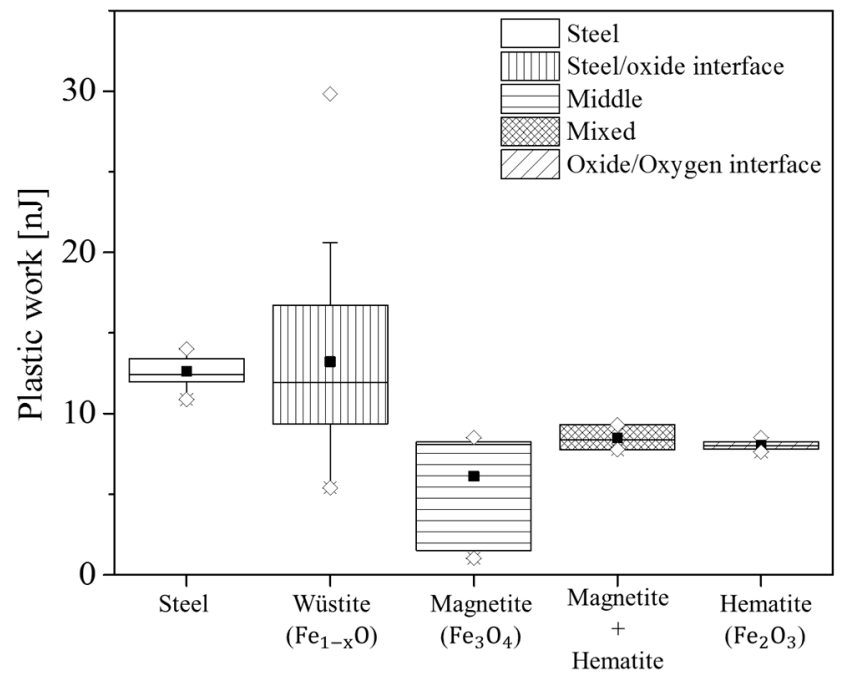

Figure 18. Plastic work of phases in oxide scales (wüstite, magnetite and hematite) formed on a surface covered with casting powder.

Micromechanical properties such as hardness, elastic modulus and plasticity index are compared to results in Part 1 (i.e., clean surface) of this work as presented in Table 3.

Table 3. Comparison of micromechanics between a specimen covered with casting powder and results obtained from Part I of this work.

\begin{tabular}{ccccccc}
\hline \multirow{2}{*}{ Phase } & \multicolumn{2}{c}{$\boldsymbol{H}_{\boldsymbol{N}}(\mathrm{GPA})$} & \multicolumn{2}{c}{ E (GPa) } & \multicolumn{2}{c}{ Plasticity Index } \\
\cline { 2 - 7 } & This Work & Part I & This Work & Part I & This Work & Part I \\
\hline Wüstite & 2.8 & 2.7 & 98 & 138 & 0.79 & 0.86 \\
Magnetite & 5.9 & 5 & 146 & 144 & 0.53 & 0.78 \\
Hematite & 6.4 & 5.5 & 141 & 150 & 0.71 & 0.75 \\
\hline
\end{tabular}

The results for clean surfaces (discussed in Part 1) revealed that temperature and time do not have a direct influence on the micromechanics of the oxide scales. Comparisons between clean surface versus covered with powder demonstrate that the micromechanics in wüstite do not have significant changes when the surface is covered with casting powder. However, differences are found for magnetite and hematite. Magnetite shows higher $H_{N}$ for the specimen covered with casting powder (5.9 GPa) than the one obtained with a clean surface (Part 1) (5.0 GPa). The elastic modulus and the plasticity index for both cases revealed similar values. In addition, hematite formed on a specimen covered with casting powder shows higher $H_{N}(6.4 \mathrm{GPa})$ when compared to a clean surface (Part 1) where lower values are obtained $(5.5 \mathrm{GPa})$. These differences can be related to the oxides and carbonates from the casting powder that diffuse through the oxide scale and modify its properties.

These findings are of considerable significance to the actual casting process due to their significant effect on the surface quality of steel slabs. Clearly, wüstite exhibits higher plasticity than magnetite and hematite [5]. This more ductile phase makes it harder to detach during bending and straightening in the casting process. Thus, wüstite is likely to get entrapped in oscillation marks, cracks, or the strand surface itself which disturbs cooling by inducing an additional resistance to heat transfer. Moreover, wüstite has a high affinity with oxygen, because it is the first phase to form on the steel substrate with a faster diffusional transport of oxygen than magnetite and hematite. Such fast wüstite transformation leads to the development of defects in the oxide layer. These include porosity during diffusion of iron ions when the steel surface is non-homogeneous nor clean enough [26,39-41]. 


\subsection{Effect of Carbon Content on Oxidation Behaviour}

Alloying elements during oxidation play an important role even though they are not directly involved in oxide scale formation. The effect of carbon can be mainly observed in the so-called decarburization phenomena that manifest during processes performed at high temperatures (i.e., $>700{ }^{\circ} \mathrm{C}$ ) $[3,8,28]$. The effect of carbon on oxidation was evaluated by means of carbon content through the oxide scale via elemental analysis (EDX). The qualitative elemental analysis was performed point-by-point (point and ID method) through the oxide scale (i.e., from the outer to the inner layer), which provides an approximation of the carbon distribution in the oxide scale, see Figure 19a.

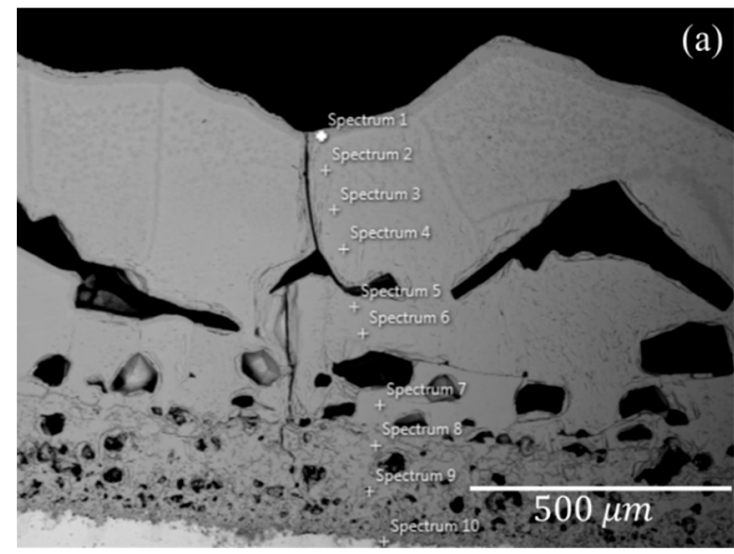

(b)

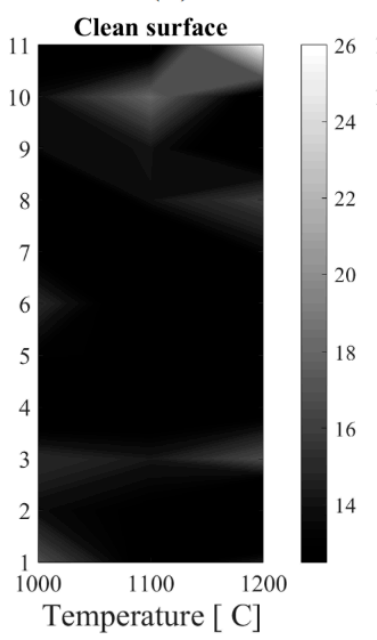

(c)

As-cast surface

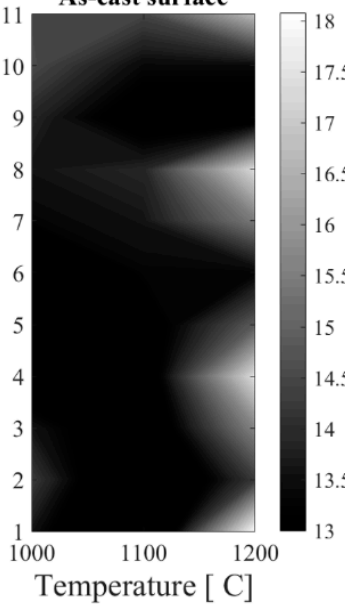

(d)

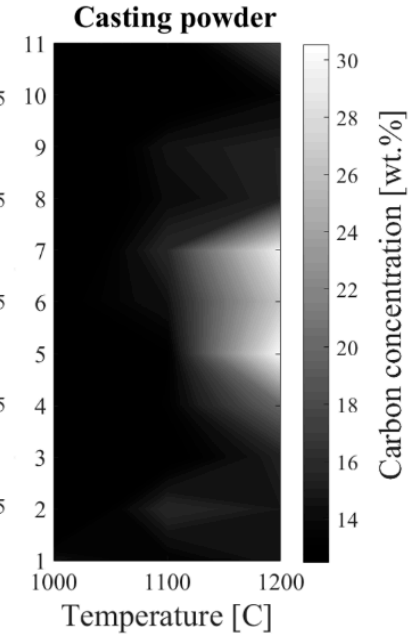

Figure 19. Energy Disperse X-ray analysis (SEM-EDX) (a) of carbon distribution (b-d) in oxide scales formed under water-vapour conditions.

The findings suggest that carbon content in the oxide scale increases with temperature (Figure 19b-d). It has been discussed that oxidation is not only influenced by temperature and atmospheric conditions (i.e., where main interactions are between the iron with oxygen in the atmosphere to form scale), but also influenced by the surface condition. Moreover, the clean surfaces exhibit low carbon content, as can be seen in Figure 19b. It can be observed that the carbon content increases as the steel surface is altered (e.g., as-cast and covered with casting powder). In contrast, the carbon content decreases but is homogeneously distributed at the highest temperature $\left(1200{ }^{\circ} \mathrm{C}\right)$ for the as-cast surface (Figure 19c). The highest amount of carbon, was present for specimens oxidized with casting powder, which mostly accumulates at the centre of the oxide scale, see Figure 19d. Accordingly, carbon from the steel oxidizes at high temperatures leading to decarburization, especially at 1100 and $1200^{\circ} \mathrm{C}$. Additionally, carbon from the casting powder influences the oxidation rate through the oxide scale, this being the reason for the high content and thicker oxide scales for clean and as-cast surfaces. 
In principle, during the $\mathrm{CC}$ process, the carbon from the casting powders combust with oxygen and $\mathrm{CO}_{2}$ to form $\mathrm{CO}$ in the slag bed between 500 and $900{ }^{\circ} \mathrm{C}$ Here, mineral particles form a sintered layer [24]. This can explain the differences between carbon content found between the as-cast and surface covered with casting powder. Indeed, the carbon in the as-cast surface combusts and dissipates during casting resulting in a minor effect during oxidation while a significant effect is found when oxidizing specimens with casting powder (in solid-state). In this case, the carbon in the casting powder does not have enough time to combust and dissipate; instead, it diffuses through the oxide scale resulting in high carbon content.

Previous studies have related decarburization to adherence and defects in oxide scales. The formation of $\mathrm{CO}$ and $\mathrm{CO}_{2}$ due to the reduction in carbon coming from the steel or casting powder influence the gas pressures during scale growth; this, in turn, promotes defects causing the detachment (also known as spallation) of the scale [8]. High pressures coming from $\mathrm{CO}$ and $\mathrm{CO}_{2}$ have been reported to cause stresses during scale formation that create voids interrupting the oxidation rate until cracks are formed [3].

\section{Conclusions}

The effect of surface conditions on the high-temperature oxidation of an HSLA steel was assessed by oxidizing specimens under dry air and water-vapour conditions at temperatures similar to those in continuous casting (i.e., below the mould, bender and straightener, 1200,1100 and $1000{ }^{\circ} \mathrm{C}$, respectively). Three different surface conditions were analysed, including: clean, as-cast and covered with casting powder. The following conclusions can be drawn from the analysis:

- Oxide scales are influenced not only by temperature and environmental conditions but also strongly by the status of the surface which increases rugosity or oxidation rate.

- Thick and dense scales are formed oxide under water vapour compared to dry air conditions.

- Scale thickness is more significant on as-cast and surface covered with casting powder than those formed on a clean surface.

- Fast oxidation and gases $\left(\mathrm{CO}\right.$ and $\left.\mathrm{CO}_{2}\right)$ lead to stress accumulation, which make oxide scales prone to defects such as pores, voids and micro-cracks. The number of these defects increase with temperature, being more pronounced in the as-cast and surfaces covered with casting powder.

- Oxides and carbonates from the casting powder during melting and sintering accelerate the oxidation rate of oxide scale leading to thick and unstable scales.

Ultimately, the mechanical properties of wüstite make it harder to detach from the as-cast or powdered surfaces which may lead to alterations in heat transfer during secondary cooling if it remains attached to the surface or infiltrates into oscillation marks or cracks. This may affect the efficiency of the secondary cooling and disturb further processing (e.g., rolling), by requiring further scarfing or de-scaling, respectively. Therefore, accurate insights on scale type and formation mechanisms could lead to the accurate control of its formation during casting. This has deep industrial implications in terms of crack formation and the overall yield of the continuous casting machine. These and other factors are being addressed by the authors in ongoing research.

Author Contributions: Funding acquisition, M.K.; investigation, R.M.P.H.; methodology, P.N.J. and L.P.; supervision, P.E.R.L. and E.V. All authors have read and agreed to the published version of the manuscript.

Funding: This research received no external funding.

Acknowledgments: Authors are grateful for the economical and scientific support provided by the following organizations and colleagues. R.M.P.H. thanks the National Council on Science and Technology (CONACYT) for economical support for her PhD studies. R.M.P.H. thanks to SWERIM for support during PhD studies and plant trials. In addition, R.M.P.H. thanks to Joar Draxler for his contribution in the discussion part. Finally, R.M.P.H. thanks to Pushkar D. and Celia M. for the contribution during their MSc. studies.

Conflicts of Interest: The authors declare no conflict of interest. 


\section{References}

1. Hu, P.; Ying, L.; Li, Y.; Liao, Z. Effect of oxide scale on temperature-dependent interfacial heat transfer in hot stamping process. J. Mater. Process. Technol. 2013, 213, 1475-1483. [CrossRef]

2. Li, Y.H.; Sellars, C.M. Comparative investigations of interfacial heat transfer behaviour during hot forging and rolling of steel with oxide scale formation. J. Mater. Process. Technol. 1998, 80-81, 282-286. [CrossRef]

3. Marston, H.F.; Bolt, P.H.; Leprince, G.; Röder, M.; Klima, R.; Niska, J.; Jarl, M. Challenges in the modelling of scale formation and decarburisation of high carbon, special and general steels. Ironmak. Steelmak. 2004, 31, 1. [CrossRef]

4. Sun, W.; Tieu, A.K.; Jiang, Z.; Lu, C. High temperature oxide scale characteristics of low carbon steel in hot rolling. J. Mater. Process. Technol. 2004, 155-156, 1307-1312. [CrossRef]

5. Hidaka, Y.; Anraku, T.; Otsuka, N. Deformation of iron oxides upon tensile tests at $600-1250{ }^{\circ} \mathrm{C}$. Oxid. Met. 2003, 59, 97-113. [CrossRef]

6. Abuluwefa, H.; Guthrie, R.; Ajersch, F. The effect of oxygen concentration on the oxidation of low-carbon steel in the temperature range 1000 to $1250{ }^{\circ} \mathrm{C}$. Oxid. Met. 1996, 46, 423-440. [CrossRef]

7. Suarez, L.; Houbaert, Y.; Eynde, X.V.; Colás, R. High temperature deformation of oxide scale. Corros. Sci. 2009, 51, 309-315. [CrossRef]

8. Chen, R.; Yeun, W. Review of the high-temperature oxidation of iron and carbon steels in air or oxygen. Oxid. Met. 2003, 59, 433-468. [CrossRef]

9. Liu, S.; Tang, D.; Wu, H.; Wang, L. Oxide scales characterization of micro-alloyed steel at high temperature. J. Mater. Process. Technol. 2013, 213, 1068-1075. [CrossRef]

10. Wang, N.; Wen, H.; Huang, W.; Dou, N.; Chen, M. Effect of Steel Composition on the Scale Layer Composition in Continuous Casting. In Proceedings of the 8th Pacific Rim International Congress on Advanced Materials and Processing, Waikoloa, HI, USA, 4-9 August 2013.

11. Chabičovský, M.; Hnízdil, M.; Tseng, A.; Raudenský, M. Effects of oxide layer on Leidenfrost temperature during spray cooling of steel at high temperatures. Int. J. Heat Mass Transf. 2015, 88, 236-246. [CrossRef]

12. Chabičovský, M.; Horský, J. Factors influencing spray cooling of hot steel surfaces. In Proceedings of the 26th International Conference on Metallurgy and Materials, Brno, Czech Republic, 24-26 May 2017.

13. Brožová, T.; Chabičovský, M.; Horský, J. Influence of the surface roughness on the cooling intensity during spray cooling. In Proceedings of the 25th Anniversary International Conference on Metallurgy and Materials, Brno, Czech Republic, 25-27 May 2016.

14. Scale Control. Control of Scale during Steel Processing; RFSR-CT-2005-00016; European Commission: London, UK, 2005.

15. ODS-STEEL. Novel Oxide Dispersion Strengthened Steels Obtained by High Productivity Casting Process with Innovative Injection of Suitable Special Powder; RFSR-CT-2006-00020; European Commission: Roma, Italy, 2006.

16. Wendelstorf, R.; Spitzer, K.; Wendelstorf, J. Effect of oxide layers on spray water cooling heat transfer at high surface temperatures. Int. J. Heat Mass Transf. 2008, 51, 4892-4901. [CrossRef]

17. Yamauchi, A.; Sorimachi, K.; Sakuraya, T.; Fujii, T. Heat transfer between mold and strand through mold flux film in continuous casting of steel. ISIJ Int. 1993, 33, 140-147. [CrossRef]

18. Bolender, T.; Cappel, J. Continuous casting without secondary spray water cooling. Steel Grips 2004, 2, 1-6.

19. Sun, W.; Tieu, A.; Jiang, Z.; Zhu, H.; Lu, C. Oxide scales growth of low-carbon steel at high temperatures. J. Mater. Process. Technol. 2004, 155-156, 1300-1306. [CrossRef]

20. Xie, Q.; Huang, Z.; Hou, Q.; Zhang, L.; Cai, J. Heat Transfer from a Hot Steel Plate Impinged by Air-atomized Water Jet and Impinging Water Jet. ISIJ Int. 2019, 59, 113-121. [CrossRef]

21. Warzee, M.; Hennaut, J.; Maurice, M.; Sonnen, C.; Waty, J.; Berge, P. Effect of Surface Treatment on the Corrosion of Stainless Steels in High-Temperature Water and Steam. J. Electrochem. Soc. 1965, $112,7$. [CrossRef]

22. Cissé, S.; Laffont, L.; Tanguy, B.; Lafont, M.; Andrieu, E. Effect of surface preparation on the corrosion of austenitic stainless steel 304L in high temperature steam and simulated PWR primary water. Corros. Sci. 2012, 56, 209-216. [CrossRef]

23. Cooper, L.; Benhaddad, S.; Wood, A.; Ivey, D. The effect of surface treatment on the oxidation of ferritic stainless steels used for solid oxide fuel cell interconnects. J. Power Sources 2008, 184, 220-228. [CrossRef] 
24. Mills, K.C.; Däcker, C. The Casting Powders Book; Mills, K.C., Däcker, C., Eds.; Springer: Cham, Switzerland, 2017.

25. Saleem, S. On the Surface Quality of Continuously Cast Steels and Phosphor Bronzes. Ph.D. Thesis, KTH Royal Institute of Technology, Stockholm, Sweden, 2016.

26. Kofstad, P. High Temperature Corrosion; Elsevier Applied Science Publishers: Essex, UK, 1988.

27. Krzyzanowski, M.; Beynon, J.H.; Farrugia, D.C. Oxide Scale Behavior in High Temperature Metal Processing; Krzyzanowski, M., Beynon, J.H., Farrugia, D.C., Eds.; John Wiley \& Sons: Hoboken, NJ, USA, 2010.

28. Young, D.J. High Temperature Oxidation and Corrosion of Metals; Young, D.J., Ed.; Elsevier: Amsterdam, The Netherlands, 2008.

29. Srinivasan, M. Science and Technology of Casting Processes; Srinivasan, M., Ed.; BoD-Books on Demand: Norderstedt, Germany, 2012.

30. Marschall, I.; Kölbl, N.; Harmuth, H.; Atzenhofer, C. Identification of secondary raw materials in mold powders and their melting behavior. J. Iron Steel Res. Int. 2019, 26, 403-411. [CrossRef]

31. Kudlinski, Z.; Sosnowski, R.; Sikora, B.; Dankmeyer-Laczny, J. The influence of the molten casting powder on the steel surface phenomena in continuous casting mould. Acta Metall. Slovaca (Slovak Repub.) 2001, 7, 184-197.

32. Yan, W.; Chen, W.; Carsten, L.; Zheng, H. Effect of Properties Change of Mold Flux and Slag Rim on Concasting of Non-Magnetic Steel 20Mn23AlV. Teshugang (Special Steel) 2013, 34, 45-48.

33. Petzow, G. Metallographic Etching: Techniques for Metallography, Ceramography, Plastography; Petzow, G., Ed.; ASM International: Cleveland, OH, USA, 1999.

34. Walker, P.; Tarn, W.H. CRC Handbook of Metal Etchants; Walker, P., Tarn, W.H., Eds.; CRC Press: Boca Raton, FL, USA, 1990.

35. Oliver, W.C.; Pharr, G.M. An improved technique for determining hardness and elastic modulus using load and displacement sensing indentation experiments. J. Mater. Res. 1992, 7, 1564-1583. [CrossRef]

36. Zambrano, O.; Coronado, J.; Rodríguez, S. Mechanical properties and phases determination of low carbon steel oxide scales formed at $1200 \mathrm{C}$ in air. Surf. Coat. Technol. 2015, 282, 155-162. [CrossRef]

37. Monazam, E.R.; Breault, R.W.; Siriwardane, R. Kinetics of hematite to wustite by hydrogen for chemical looping combustion. Energy Fuels 2014, 28, 5406-5414. [CrossRef]

38. Pitschke, W.; Hermann, H.; Mattern, N. The influence of surface roughness on diffracted X-ray intensities in Bragg-Brentano geometry and its effect on the structure determination by means of Rietveld analysis. Powder Diffr. 1993, 8, 74-83. [CrossRef]

39. Parkinson, G.S. Iron oxide surfaces. Surf. Sci. Rep. 2016, 71, 272-365. [CrossRef]

40. Hallström, S.; Höglund, L.; Agren, J. Modeling of iron diffusion in the iron oxides magnetite and hematite with variable stoichiometry. Acta Mater. 2011, 59, 53-60. [CrossRef]

41. Giletti, B.; Hess, K. Oxygen diffusion in magnetite. Earth Planet. Sci. Lett. 1988, 89, 115-122. [CrossRef] 